\title{
EFEITO DO CÁLCIO NA QUALIDADE ÓSSEA E DE OVOS DE POEDEIRAS
}

\author{
CALCIUM EFFECT IN BONE AND EGG QUALITY OF THE HENS
}

\begin{abstract}
Almeida Paz, I.C.L. ${ }^{1}$, A.A. Mendes ${ }^{2 A}$, A. Balog ${ }^{2 B}$, C.M. Komiyama ${ }^{2 C}$, S.E. Takahashi2 ${ }^{2 D}$, I.C.L. Almeida ${ }^{2 E}$, E.A. Garcia ${ }^{2 F}$, L.C. Vulcano ${ }^{3}$, A.W. Ballarin ${ }^{4}$, M.C. Silva ${ }^{2 G}$ e K.F.G. Cardoso ${ }^{2 H}$

${ }^{1}$ Departamento de Produção Animal. Faculdade de Medicina Veterinária e Zootecnia. Universidade Estadual Paulista. Fazenda Experimental Lageado. Botucatu, SP. CEP 18618-000. Brasil. Correspondência: ibiara@fca.unesp.br

${ }^{2}$ Departamento de Produção Animal. Faculdade de Medicina Veterinária e Zootecnia. UNESP. Botucatu. Brasil. Aarielmendes@fca.unesp.br; BButobalog@fmvz.unesp.br; 'Claudiamarie@fmvz.unesp.br; Dsaendosp@fca.unesp.br; Eibiara@fasternet.com.br; Fegarcia@fca.unesp.br; ${ }^{6}$ marleidecs@ yahoo.com.br; Hkarenfgcardoso@fmvz.unesp.br

${ }^{3}$ Departamento de Reprodução Animal e Radiologia Veterinária. Faculdade de Medicina Veterinária e Zootecnia. UNESP. Botucatu, SP. Brasil. vulcano@fmvz.unesp.br

${ }^{4}$ Departamento de Engenharia Rural. Faculdade de Ciências Agronômicas. UNESP. Botucatu, SP. Brasil. awballarin@fca.unesp.br
\end{abstract}

\section{PaLAVRAS CHAVES ADICIONAIS}

Densidade mineral. Nutrição.

\section{RESUMO}

Um experimento foi realizado com duração de 27 semanas, com poedeiras da linhagem Shaver Brown em produção, seu objetivo foi avaliar a mobilização de cálcio e fósforo ósseos para a formação da casca dos ovos, assim como, acompanhar as variações na qualidade óssea ao longo do ciclo de produção. Foram utilizadas 64 aves. O delineamento experimental foi o inteiramente casualizado com dois tratamentos (porcentagem de cálcio na dieta) e quatro repetições de oito aves cada. As dietas utilizadas foram isoprotéicas e isocalóricas, com níveis adequados $(3,8 \%)$ e baixos $(1,8 \%)$ de cálcio. Realizaram-se análises densidade mineral óssea (DMO) das tíbias e fêmures às 16, 22, 28, 34 e 40 semanas de idade. Após cada coleta radiográfica 4 aves por tratamento, foi abatida para realização de análise de resistência óssea (RO), índice Seedor (IS), teor de matéria seca (MS), teor de minerais totais (MIN) e os teores de cálcio e fósforo (Ca e $P)$. Os valores de produção de ovos, produção de massa de ovos e qualidade da casca também foram avaliados. Foi possível concluir que as aves mobilizaram minerais ósseos para a produção de

Recibido: 16-5-07. Aceptado: 1-10-07.

\section{AdDitional KeYWORDS}

Mineral density. Nutrition.

ovos, independentemente do tratamento e que as aves que receberam dietas com níveis baixos de cálcio tiveram a qualidade das cascas dos ovos prejudicadas.

\section{SUMMARY}

The experiment was carried out, with hens of the Shaver Brown strain in production, during 27 weeks. The objective was to evaluate the mobilization of bone calcium and phosphorus for the formation of the shell eggs, as well as to follow the variations in the bone quality along the production cycle. 64 birds had been used. The experimental desing was entirely randomized with two treatments (calcium percentage in the diet) and four repetitions of eight birds each. The used diets were isoproteic and isoenergetic adequate $(3.8 \%)$ and low (1.8\%) calcium levels. Analysis of bone (tibiae and femurs) mineral density (DMO) were done at 16, 22, 28, 34 and 40 weeks of age were developed. After each radiographic collection, 4 birds/treatment, were abated for the analysis of bone resistance (RO), Seedor index 
(IS), dry matter (MS), total mineral (MIN) and calcium and phosphorus ( $\mathrm{Ca}$ and $\mathrm{P}$ ). The values of egg production, production of egg mass and quality of the egg shell were also evaluated. It was possible to conclude that the birds mobilized bone minerals for the egg production, independently of the treatment and the birds receiving diets with low levels of calcium had the quality of the eggs shell damaged.

\section{INTRODUÇÃO}

O estudo da densidade mineral óssea de aves de interesse zootécnico, tem grande importância para a avicultura pois esta é uma técnica que permite o acompanhamento das variações de massa óssea com baixo custo e tecnologia moderna, auxiliando na compreensão e melhor avaliação do processo de mineralização óssea (Louzada, 1997).

A rigidez do tecido ósseo é resultante da deposição de cálcio e fósforo, na forma de hidroxiapatita, durante o processo de mineralização óssea. Esses dois minerais perfazem cerca de $70 \%$ da composição óssea, os 30\% restantes são compostos de matéria orgânica, principalmente colágeno (Kälebo e Strid, 1988a; Field, 1999; Bruno, 2002). A hidroxiapatita e o alumínio possuem densidades muito semelhantes, desta forma, muitos autores realizaram estudos com o objetivo de relacionar o grau de mineralização óssea e a densidade do alumínio e concluíram que é possível comparar, através de um estudo radiológico, a quantidade de cálcio e fósforo depositados nos ossos com a quantidade de alumínio encontrada em uma escala pré-definida (Loubel e Dubois, 1973; Kälebo e Strid, 1988a; Kälebo e Strid, 1988b). Alguns estudos utilizando a densitometria óssea, por meio de energia de raios-x, têm sido realizados por pesquisadores de diversos locais (Schreiweis et al., 2003; Onyango et al., 2003; Korver et al., 2004; Hester et al., 2004; Fleming et al., 2004; Schreiweis et al., 2004).

A densidade mineral óssea pode, ainda, ser medida através de técnicas como a composição mineral óssea, resistência óssea à quebra, índice Seedor (Seedor, 1995), entre outras (Orban et al., 1983). Em um experimento realizado com galinhas Leghorn brancas, Zhang e Coon (1997), encontraram que a força à quebra, também denominada resistência óssea, não está em função da porcentagem de cinzas ósseas, mais sim em função do volume do mesmo. O volume ósseo é considerado no cálculo do índice Seedor, ou seja, estas medidas são bastante importantes nas mensurações de qualidade óssea, estando intimamente relacionadas.

Em poedeiras a exigência de cálcio é muito elevada, particularmente durante o período ativo de formação da casca. Hester et al. (2004) encontraram aumento na densidade mineral óssea de tíbias de galinhas Leghorn entre 15 e 65 semanas de idade, sendo que, quando estas aves sofreram jejum alimentar por 10 dias ocorreu queda na densidade mineral óssea. Em um estudo realizado por Schreiweis et al. (2003), os autores verificaram a densidade mineral óssea de tíbia e úmero de galinhas Leghorn brancas submetidas a dietas com diferentes níveis de cálcio (hipercálcica 5,4\%, cálcio recomendado $3,6 \%$ e hipocálcica $1,8 \%$ ), concluindo que a densidade mineral óssea segue uma tendência linear negativa com a diminuição do cálcio da dieta. Ao avaliar a resistência óssea de fêmures e úmeros de galinhas Leghorn brancas no final do ciclo produtivo (65 semanas), Korver et al. (2004) encontraram maiores resistências para os ossos das aves marrons, talvez por essas aves serem mais pesadas que as brancas.

O objetivo deste experimento foi avaliar o efeito do cálcio dietético sobre a qualidade óssea, qualidade da casca dos ovos e produção de ovos de poedeiras semipesadas.

\section{MATERIALE MÉTODOS}

$\mathrm{O}$ experimento foi realizado nas instalações da FMVZ-UNESP/Botucatu, no período de abril a agosto de 2006 . Foram utilizadas 64 aves da linhagem Shaver Brown, as quais foram adquiridas de uma granja co- 
mercial, às 15 semanas de idade. O delineamento experimental adotado foi o inteiramente casualizado com dois tratamentos (porcentagem de cálcio na dieta) e quatro repetições de oito aves cada.

As aves receberam 17 horas de luz (natural + artificial) e água ad libtum. A coleta de ovos foi diária, realizada uma vez ao dia, às $9: 30 \mathrm{~h}$. $\mathrm{O}$ arraçoamento foi diário, sendo que o cálculo de consumo de ração foi realizado uma vez por semana. Os dados de produção diária de ovos e consumo semanal de ração foram anotados em ficha própria, divididos por gaiola. As rações utilizadas foram isoprotéicas $(16,50 \%$ de $\mathrm{PB})$ e isocalóricas $(2750 \mathrm{kcal}$ de $\mathrm{EM} / \mathrm{kg})$ e tiveram níveis adequados $(3,8 \%)$ e baixos $(1,8 \%)$ de cálcio.

\section{AVALIAÇÕESDE QUALIDADE ÓSSEA}

Foram realizadas análises de densidade mineral óssea (DMO) das tíbias e fêmures direitos das aves às 16, 22, 28, 34 e 40 semanas de idade, na ocasião foram tomadas ao acaso, 64 aves que formaram o grupo de análise. Antes de cada coleta de imagens radiográficas as aves do grupo de análise foram pesadas individualmente, em balança com precisão de $2 \mathrm{~g}$, posteriormente estas aves foram transportadas ao Hospital Veterinário da FMVZ, onde foram radiografadas com o auxílio de um aparelho de Raio-X, calibrado e com distância foco-filme de $90 \mathrm{~cm}$, a técnica radiográfica utilizada foi $36 \mathrm{kVp} \times 1,6 \mathrm{mAs}$.

Todos os filmes radiográficos utilizados foram da mesma marca, de base verde e chassi de 24 x $30 \mathrm{~cm}$ equipados com ecrans de terras-raras. Paralelamente, e distante 3,0 $\mathrm{cm}$ da região radiografada, foi colocada uma escala de alumínio (phantom) que foi utilizada como referencial densitométrico. O phanton é constituído por 20 degraus de alumínio, sendo que o primeiro degrau possui $0,5 \mathrm{~mm}$ de espessura, variando a seguir de 0,5 em $0,5 \mathrm{~mm}$ até o vigésimo degrau, cada degrau com área de $15 \mathrm{~mm}$ x $5 \mathrm{~mm}$.

Os procedimentos radiológicos utiliza- dos foram os de rotina clínica e o processo de revelação e fixação foi realizado em um processador automático padrão.

A região padronizada para a realização da leitura foi a epífise proximal da tíbia e distal do fêmur direitos das aves. As leituras de densidade óptica em imagens radiográficas (densidade mineral óssea) foram realizadas por meio do Programa CROMOX ${ }^{\circledR}$ ATHENA 3.1 - SIA.

Depois de radiografadas, quatro aves por tratamento foram abatidas para a retirada da perna direita e realização das demais avaliações de qualidade óssea. Para a realização da desossa das peças utilizadas no experimento, as mesmas foram devidamente identificadas e mergulhadas em água fervente por 10 minutos. Posteriormente foram desossadas com auxílio de bisturi, conforme metodologia descrita por Bruno (2002). Utilizando este método de desossa é possível extrair cerca de $80 \%$ da gordura presente.

Para a realização das avaliações de resistência óssea foi utilizado o aparelho de teste de ensaio EMIC DL 10000, o qual foi regulado para permitir que o vão livre da diáfise fosse de $3,0 \mathrm{~cm}$. Este valor foi $\mathrm{o}$ espaçamento máximo conseguido para o menor osso encontrado, sendo desta forma fixado para os demais ossos do estudo. Somente com a fixação de um vão livre para a realização das avaliações de resistência pode-se comparar os valores (kgf) encontrados (Almeida Paz et al., 2006). O índice Seedor, que é o valor obtido ao se dividir o peso do osso por seu comprimento, conforme proposto inicialmente por Seedor (1995), serve como indicativo da densidade óssea, quanto maior o valor, mais denso é o osso. Para a realização desta avaliação, os ossos foram medidos em seu maior comprimento, com o auxílio de um paquímetro e tiveram seu peso obtido com o auxilio de uma balança semi-analítica digital.

A obtenção da porcentagem de matéria seca foi realizada pesando-se os ossos em balança analítica digital. Após este proce- 


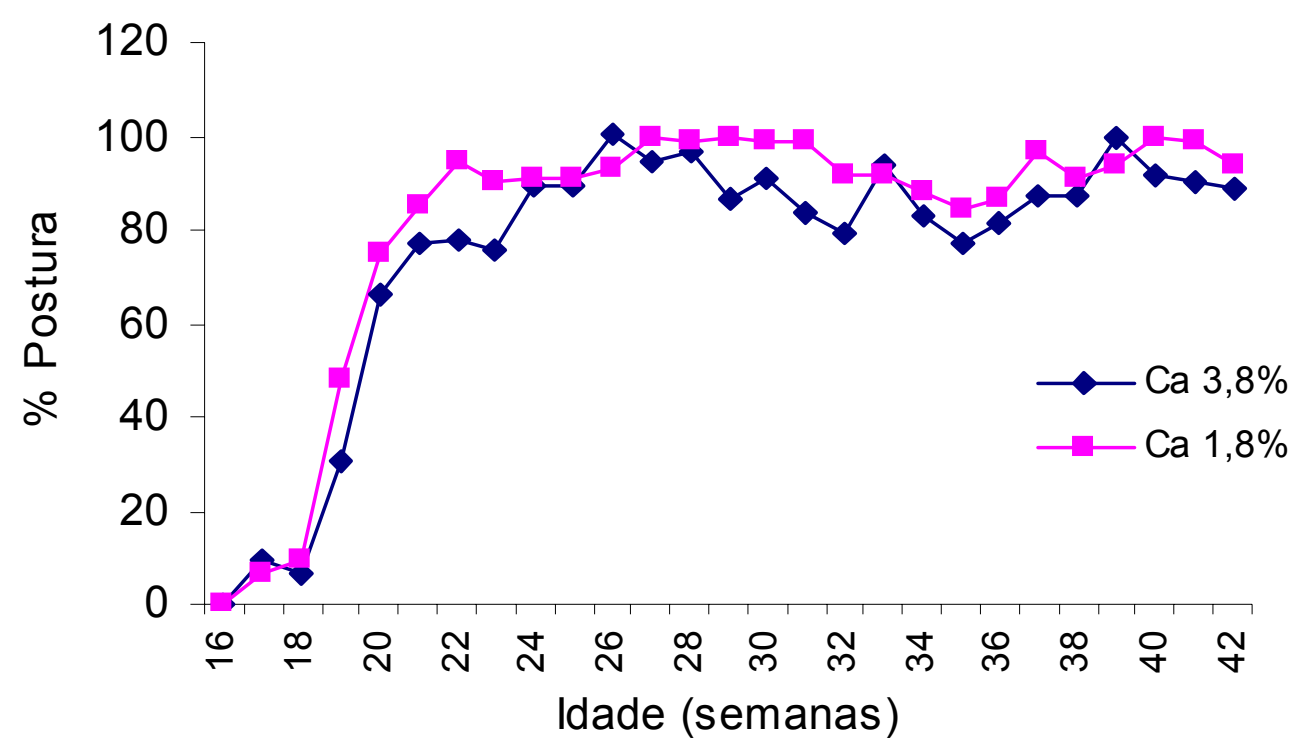

Figura 1. Produção de ovos das aves estudadas, segundo os tratamentos. (Egg production of the studied hens, according to treatments).

dimento, os ossos foram secos por 72 horas em estufa de ventilação forçada à $105^{\circ} \mathrm{C}$, após esfriarem foram pesados novamente, a diferença entre o peso correspondeu ao teor de matéria seca desengordurada, expresso em porcentagem, conforme metodologia descrita por Kim et al. (2004). Posteriormente, estas amostras foram pesadas novamente e levadas à mufla, onde foram submetidos à temperatura de $600^{\circ} \mathrm{C}$ por $24 \mathrm{~h}$, para obtenção do teor de minerais totais.

As concentrações de cálcio dos ossos foram determinadas por espectrofotometria de absorção atômica e as concentrações de fósforo foram determinadas por colorimetria.

\section{AVALIAÇÃO DA QUALIDADE DA CASCA DOS OVOS}

Esta análise foi realizada com os ovos obtidos no dia anterior e no dia da coleta de imagens radiográficas. Para isso os ovos, devidamente identificados, foram submetidos à análise de peso específico e porcentagem de casca. Para obtenção do peso específico foram elaboradas nove soluções salinas com densidades de 1,060; 1,065; 1,$070 ; 1,075 ; 1,080 ; 1,085 ; 1,090 ; 1,095$ e 1,100 e colocadas em ordem crescente em recipientes identificados, à temperatura de $15^{\circ} \mathrm{C}$. Primeiramente os ovos foram colocados no recipiente de 1,060 , e assim sucessivamente, até que os ovos flutuassem na solução (Castelló et al., 1989). O peso específico foi representado pela solução de menor densidade onde o ovo emergiu. A porcentagem de casca foi obtida considerando-se o peso total do ovo e o peso da casca, o qual foi medido após as cascas serem secas em estufa a $60^{\circ} \mathrm{C}$ por 3 dias, conforme metodologia descrita por Castelló et al. (1989).

\section{ANÁLISE ESTATíSTICADOSRESULTADOS}

As análises estatísticas foram realizadas com o auxílio do programa estatístico SAEG (1998). As características de qualidade óssea e qualidade da casca dos ovos, dentro dos tratamentos utilizados, foram submetidas à análise de variância e suas 
médias comparadas pelo teste de Tukey a 95\% de probabilidade. Posteriormente, as características de qualidade óssea, qualidade de casca de ovos e produção foram submetidas à correlação de Pearson $(5 \%$ de significância). A idade das aves foi utilizada como co-variável. As curvas de produção de ovos e de massa de ovos e DMO de tíbia e fêmures foram ajustadas por equações de regressão.

\section{RESULTADOSEDISCUSSÃO}

Para porcentagem de postura houve efeito $(\mathrm{p}<0,05)$ apenas da idade das aves, sendo que no período inicial de produção (17 a 22 semanas de idade) a porcentagem de postura foi menor que nos demais períodos (figura 1). Isto ocorreu pois no período inicial as aves estavam entrando em produção e mantiveram seu índice produtivo até o fim do experimento, uma vez que a linhagem utilizada tem grande persistência de postura e o teste não foi levado até o período final de produção, que ocorre com cerca de 64 semanas. Porém, a produção de ovos das aves, independente do tratamento foi aquela preconizada pelo manual da linhagem (Shaver Brown, 2005) e encontrada na literatura (Maggioni et al., 1996). O consumo de ração não sofreu influência do tratamento, ou seja, as aves consumiram a mesma quantidade de ração, independente do nível de cálcio. A produção de massa de ovos das aves que se alimentaram com a dieta contendo níveis baixos de cálcio foi menor que àquelas encontradas para as aves alimentadas com a dieta contendo o nível ideal de cálcio (figura 2). O grupo de aves alimentadas com nível adequado de cálcio teve um aumento gradativo na produção de massa de ovos, com o aumento da idade das aves. Já o grupo de aves que foi alimentado com nível baixo de cálcio apresentou a menor produção da massa de ovos no período entre 15 e 28 semanas. Segundo Etches (1995), a casca dos ovos é composta por $2,00 \%$ de matriz glicoprotéica e $98,00 \%$ de bicarbonato de cálcio, sendo que $40 \%$ desta molécula é formada por cálcio, desta forma, o peso do ovo é influenciado pelo peso de sua casca. A casca, por sua vez

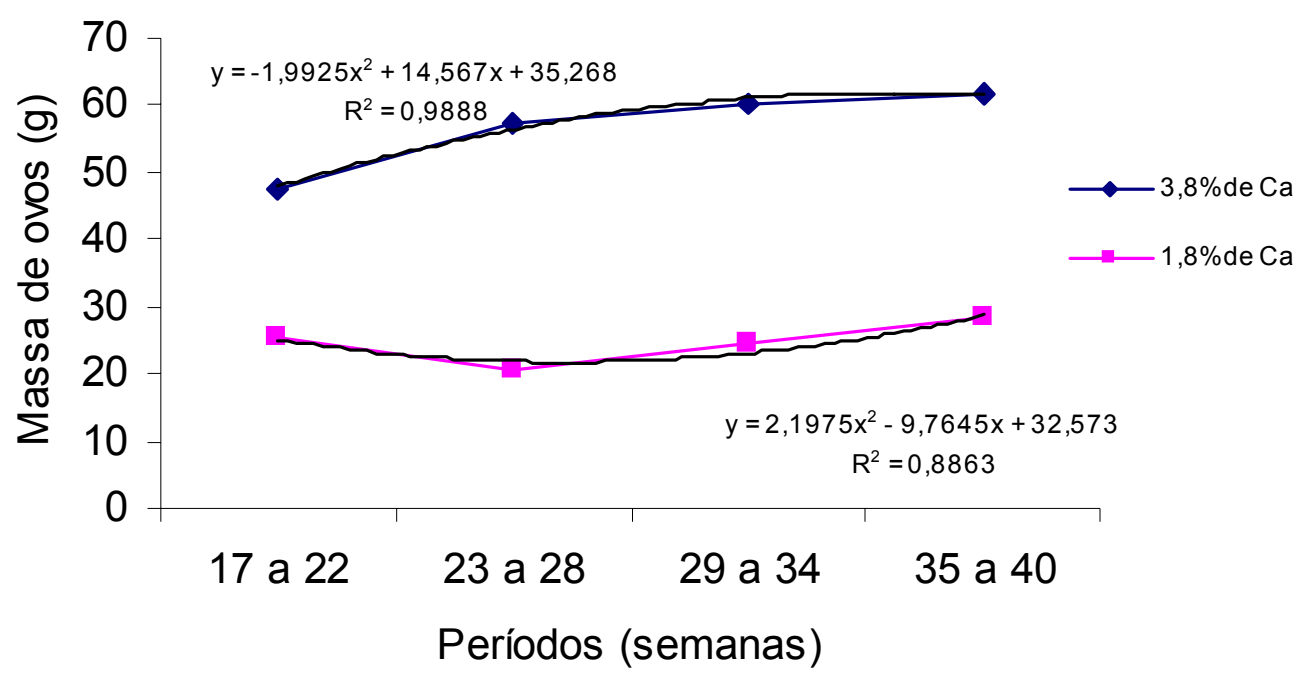

Figura 2. Produção de massa de ovos de poedeiras semi pesadas submetidas à níveis normais e baixos de cálcio na dieta. (Production of egg mass of hens submitted to the normal and low levels of calcium in the diet). 
é formada por carbonato de cálcio e participa de cerca de 8 a $10 \%$ do peso do ovo, quando as aves são submetidas à restrição de cálcio o peso do ovo tende a diminuir e a qualidade da casca piorar (Castelló et al., 1989; Qin e Klandorf, 1991; Robinson et al. 1993). Observando as curvas de regressão é possível verificar que a produção de massa de ovos apresentou comportamento quadrático $(p<0,05)$. Sendo que o grupo que recebeu nível adequado de cálcio na dieta, comportou-se conforme descrito na literatura (Oliveira et al., 2002; Shaver Brown, 2005).

Foi possível verificar que o peso dos ovos sofreu influência $(p<0,05)$ da idade e dos níveis de cálcio na dieta. Sendo que o peso foi maior para os ovos das aves alimentadas com o nível normal de cálcio $(3,8 \%$ de Ca), com um valor médio de 1087 , já as aves que foram alimentadas com nível baixo de cálcio apresentaram valor médio de peso específico de 1057, o peso também foi maior com o aumento da idade para ambos os tratamentos. Para peso específico (ou gravidade específica), houve efeito de tratamento e idade de coleta $(\mathrm{p}<0,05)$, sendo que o tratamento com nível adequado de cálcio $(3,8 \% \mathrm{de} \mathrm{Ca})$ proporcionou maior peso específico. Para idade, o peso específico foi o maior às 22 e 28 semanas, diminuindo às 34 semanas e voltando a elevar-se às 40 semanas de idade, porém sem alcançar os valores iniciais. Para porcentagem de casca, houve interação $(\mathrm{p}<0,05)$ entre idade e nível de cálcio na dieta, sendo que as aves alimentadas com níveis baixos de cálcio $(1,8 \%)$ apresentaram os menores valores, principalmente às 34 semanas de idade. Na figura 2, é possível verificar a curva de regressão para porcentagem de casca. O tratamento com 3,8\% de cálcio na dieta apresentou regressão linear negativa $(p<0,05)$. Já, o tratamento com $1,8 \%$ de cálcio na dieta apresentou regressão quadrática negativa $(\mathrm{p}<0,05)$, demonstrando que a qualidade de casca sofreu uma piora e depois se readequou.
Na tabela I, encontram-se os valores de DMO segundo os tratamentos utilizados. Foi possível verificar que os fêmures apresentaram valores mais elevados de densidade mineral óssea que as tíbias, independentemente do tratamento e da idade das aves. Houve diferença entre os tratamentos, para a densidade de tíbias e fêmures, sendo que os ossos das aves alimentadas com os valores normais de cálcio $(3,80 \%)$ apresentaram-se mais densos que aqueles pertencentes às aves alimentadas com $1,80 \%$ de cálcio. Em uma análise geral, verifica-se que a densidade óssea das aves seguiu o comportamento da produção de ovos, até a $34^{\mathrm{a}}$ semana de idade, com densidade óssea menor antes da postura e variações na densidade conforme a produção de ovos. Porém, às 40 semanas de idade a densidade mineral óssea de tíbias e fêmures aumentou, independente do tratamento e a produção de ovos continuou estável. Segundo Hudson et al. (2000), deficiências nutricionais podem causar queda na produção e qualidade dos ovos, aumentando a mobilização de cálcio ósseo, este efeito parece ter acontecido até 34 semanas.

Na tabela II estão os valores médios de resistência óssea, índice Seedor, matéria seca, teores de minerais totais, cálcio e fósforo e também a relação entre cálcio e fósforo das tíbias e fêmures das poedeiras semi pesadas estudadas. Foi possível verificar que não houve diferença $(\mathrm{p}>0,05)$ entre os tratamentos para as características de resistência óssea, índice Seedor e matéria seca de tíbias e fêmures. Houve, sim, diferença $(p<0,05)$ entre as idades das aves, sendo que ambos os tratamentos comportaram-se de forma semelhante. Para resistência óssea e matéria seca houve uma diminuição nos valores, para tíbias e fêmures, com o aumento da idade das aves. Para índice Seedor apenas houve diferença entre as idades para tíbias, com aumento nos valores às 22 semanas de idade, ou seja, quando as aves estavam entrando em

Archivos de zootecnia vol. 58, núm. 222, p. 178. 
Tabela I. Valores médios de densidade mineral óssea (DMO) e peso, obtidos em poedeiras, segundo o nível de cálcio na dieta e a idade das aves. (Average values of bone mineral density (DMO) and weight for hens according to calcium level in the diet and age).

\begin{tabular}{|c|c|c|c|c|c|c|c|c|c|c|c|}
\hline & \multirow[b]{3}{*}{$\mathrm{Ca} \%$} & \multicolumn{10}{|c|}{ Idade (semanas) } \\
\hline & & \multicolumn{2}{|c|}{16} & \multicolumn{2}{|c|}{22} & \multicolumn{2}{|c|}{28} & \multicolumn{2}{|c|}{34} & \multicolumn{2}{|c|}{40} \\
\hline & & Tíbia & Fêmur & Tíbia & Fêmur & Tíbia & Fêmur & Tíbia & Fêmur & Tíbia & Fêmur \\
\hline \multirow{3}{*}{$\begin{array}{l}\text { DMO } \\
(\mathrm{mm} \mathrm{Al})\end{array}$} & 3,80 & $2,23^{A b}$ & $3,33^{\mathrm{Ab}}$ & $3,01^{\text {Aab }}$ & $4,77^{\text {Aab }}$ & $2,15^{\mathrm{Ab}}$ & $3,60^{A b}$ & $2,89^{A b}$ & $3,96^{\mathrm{Ab}}$ & $4,29^{\mathrm{Aa}}$ & $6,08^{\mathrm{Aa}}$ \\
\hline & 1,80 & $1,99^{\mathrm{Bb}}$ & $2,91^{\mathrm{Ba}}$ & $2,20^{\mathrm{Bab}}$ & $3,89^{\mathrm{Ba}}$ & $2,09^{\mathrm{Bb}}$ & $3,26^{\text {Bab }}$ & $2,71^{\mathrm{Ba}}$ & $3,89^{\mathrm{Ba}}$ & $3,00^{\mathrm{Ba}}$ & $4,29^{\mathrm{Ba}}$ \\
\hline & Média & 2,11 & 3,12 & 2,60 & 4,33 & 2,12 & 3,43 & 2,8 & 3,92 & 3,64 & 5,18 \\
\hline \multirow{3}{*}{$\begin{array}{l}\text { Peso } \\
\text { (g) }\end{array}$} & 3,80 & \multicolumn{2}{|c|}{$1656^{\mathrm{BC}}$} & \multicolumn{2}{|c|}{$1833^{\mathrm{Ab}}$} & \multicolumn{2}{|c|}{$1861^{\mathrm{Ab}}$} & \multicolumn{2}{|c|}{$1867^{A b}$} & \multicolumn{2}{|c|}{$1908^{\mathrm{Aa}}$} \\
\hline & 1,80 & \multirow{2}{*}{\multicolumn{2}{|c|}{$\begin{array}{c}1676^{\mathrm{Ba}} \\
1666\end{array}$}} & \multicolumn{2}{|c|}{$1731^{\mathrm{Ba}}$} & \multicolumn{2}{|c|}{$1759^{\mathrm{Ba}}$} & \multicolumn{2}{|c|}{$1787^{\mathrm{Ba}}$} & \multicolumn{2}{|c|}{$1788^{\mathrm{Ba}}$} \\
\hline & Média & & & \multicolumn{2}{|c|}{1782} & \multicolumn{2}{|c|}{1810} & \multicolumn{2}{|c|}{1824} & \\
\hline
\end{tabular}

Médias seguidas por letras minúsculas na linha, ou maiúsculas na coluna, diferem entre si por teste de Tukey (5\%).

produção, fato semelhante foi encontrado por Almeida Paz et al. (2006), em um estudo realizado com matrizes pesadas, onde a qualidade óssea foi maior no início da produção, provavelmente devido à preparação da ave, armazenando minerais, para o pico de postura. Verificou-se que o comportamento foi semelhante entre as características de qualidade óssea, independentemente do tratamento utilizado, indicando que as aves mobilizam constantemente minerais ósseos para a formação da casca dos ovos. Isto também é verificado nas correlações entre características de qualidade óssea e qualidade de casca de ovos apresentadas na tabela III. Foi possível encontrar correlações bastante elevadas entre as características de qualidade óssea, tanto para tíbias como para fêmures e, também, entre esses ossos. Os valores de índice Seedor foram aqueles que apresentaram menos correlações com as demais características. As correlações entre os valores de densidade mineral óssea de tíbias e fêmures e qualidade de ovos demonstram que os minerais ósseos foram mobilizados para a produção de ovos. A característica de densidade mineral de tíbia foi a única que apresentou correlação significativa com todas as demais características avaliadas, demonstrando ser um bom método de avaliação de qualidade óssea. As correlações entre teores de cálcio e fósforo de tíbias e fêmures apresentaram correlações entre si e entre qualidade de ovos. Apresentando correlações negativas com a produção e qualidade dos ovos, ou seja, quanto maior a produção de ovos menores os teores destes minerais nos ossos. Isto porque, a utilização de cálcio ósseo para formação da casca dos ovos ocorre quando não há disponibilidade de cálcio dietético (Agroceres Ross, 2006; Julian, 2005) e as correlações foram avaliadas independentemente do tratamento.

\section{CONCLUSÃO}

Foi possível concluir que as aves mobilizaram minerais ósseos para a produção de ovos, independentemente do nível de cálcio na dieta. E que a qualidade da casca dos ovos das aves alimentadas com níveis baixos de cálcio foi afetada. A densidade mineral de tíbias mostrou-se um bom método de avaliação de qualidade óssea. 


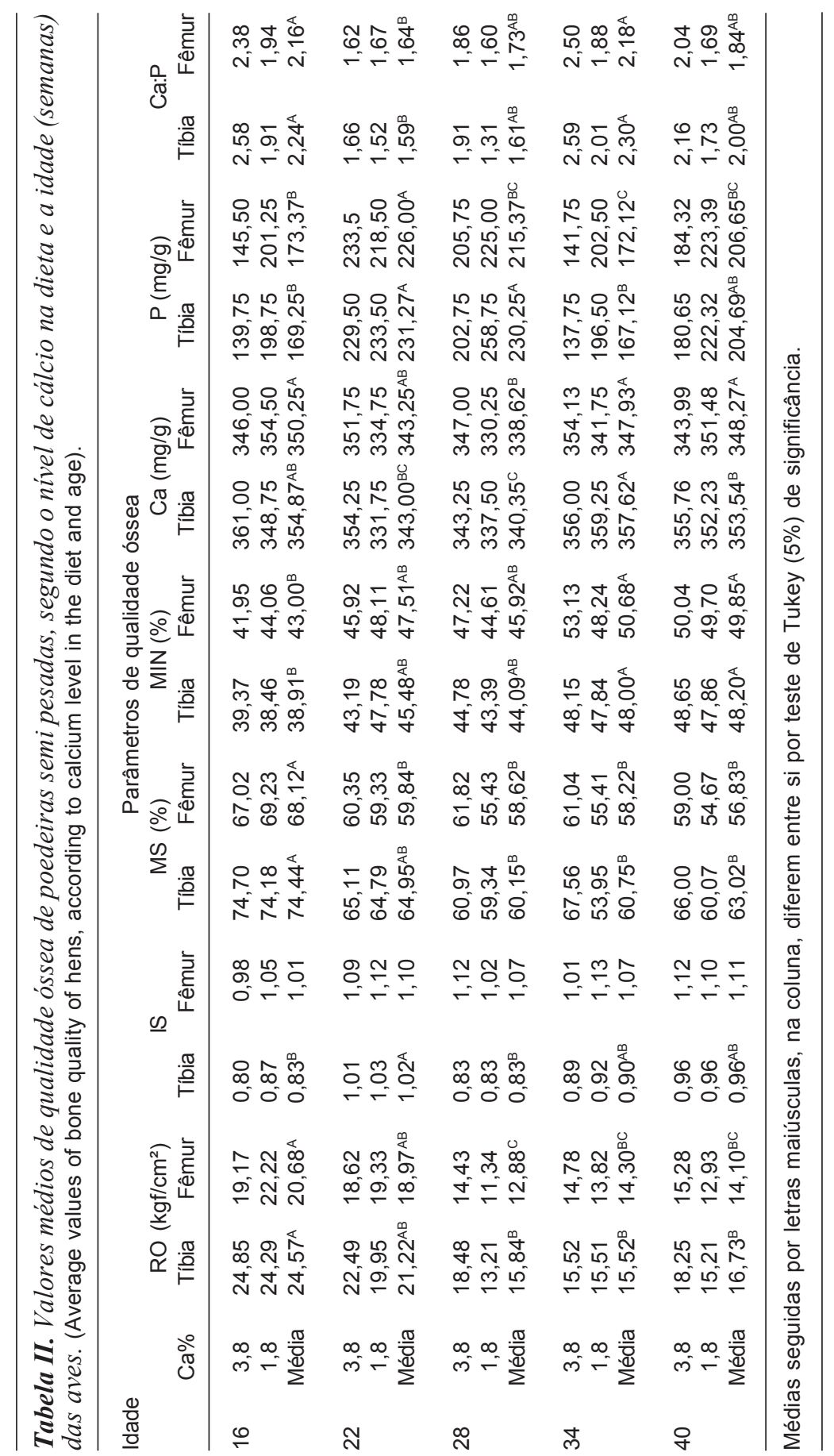


EFEITO DO CÁLCIO NA QUALIDADE ÓSSEA E DE OVOS DE POEDEIRAS

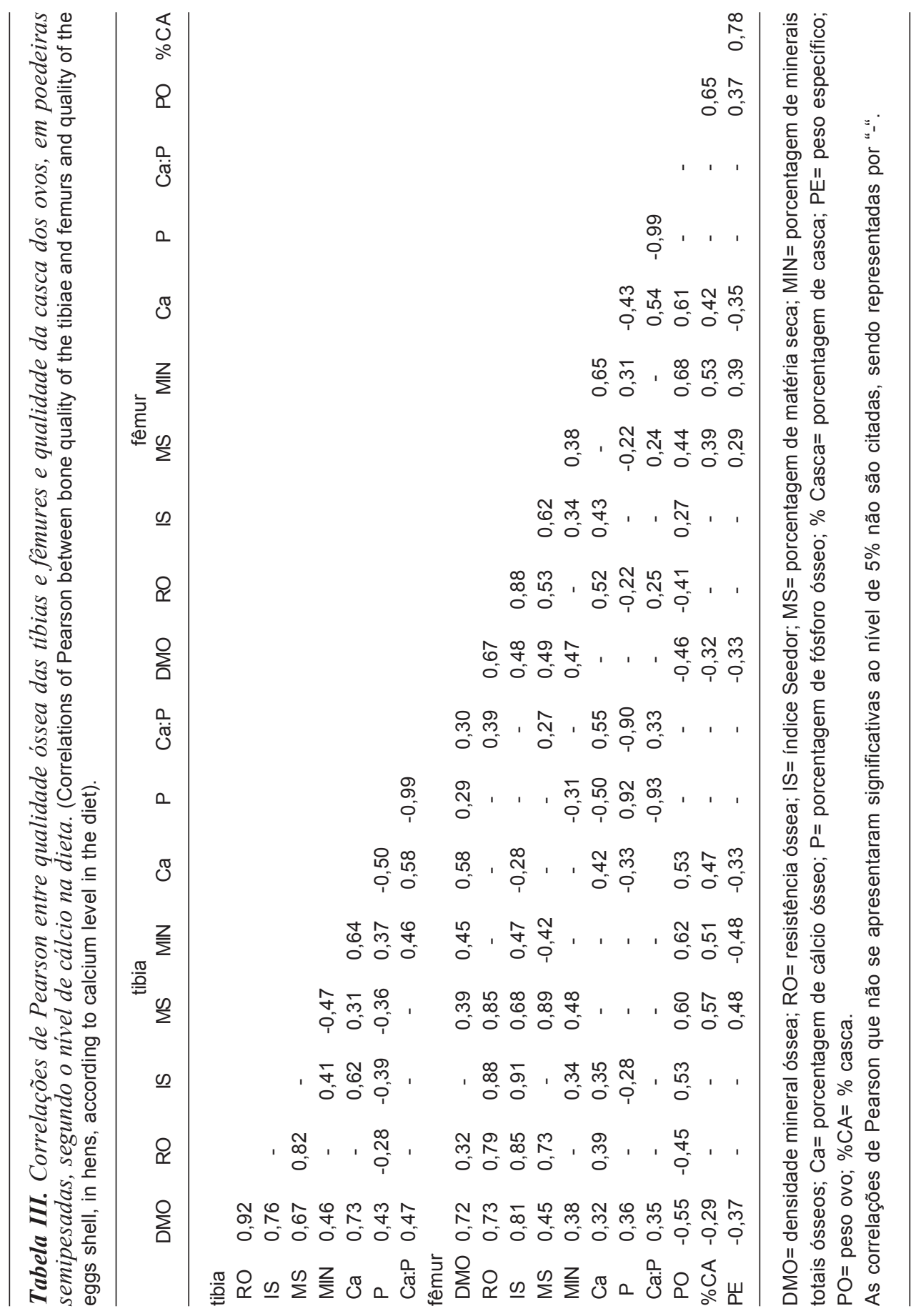

Archivos de zootecnia vol. 58, núm. 222, p. 181. 


\section{ALMEIDAPAZETAL.}

\section{BIBLIOGRAFIA}

Agroceres Ross. 2006. Manual de manejo de matrizes. Agroceres Ross Melhoramento Genético de Aves S.A. Acesso www.agroceres. com.br, em 23 de setembro de 2006.

Almeida Paz, I.C.L., A.A. Mendes, R.R. Quinteiro, L.C. Vulcano, S.E. Takahashi, R.G. Garcia, C.M. Komiyama, A. Balog, K. Pelicia, F.S. Wescheler and A. Piccinin. 2006. Bone mineral density of tibia and femur of broiler breeders: growth, development and production. Braz. J. Poultry Sci., 8: 75-82.

Bruno, L.G.D. 2002. Desenvolvimento ósseo em frangos de corte: Influência da restrição alimentar e da temperatura ambiente. Tese (Doutorado). Faculdade de Ciências Agrárias e Veterinárias, Universidade Estadual de Paulista. UNESP. Jaboticabal. $72 \mathrm{p}$.

Castelló, J.A.L., M. Pontes y F.F. González. 1989. Producción de huevos. $1^{\mathrm{a}}$ ed. Real Escuela de Avicultura. Barcelona, España. 367 p.

Etches, R.J. 1995. Reproduction in poultry. CAB International. 398 p. http://www.sciencedirect. com/science?_ob=ArticleURL\&_udi=B6T9B3WOFR4R-1F\&_user $=972052 \&$ rdoc $=1 \&$ fmt $=$ \&_orig=search\&_sort $=d \&$ view $=c \&$ \&acct $=$ C000049647\&_version $=1 \&$ \&urlVersion $=0$ \& userid $=972052 \& \mathrm{md} 5=546 \mathrm{c} 2420 \mathrm{a} 363855 \mathrm{f}$ 21baf28ae88572c5

Field, R.A. 1999. Ash and calcium as measures of bone in meat and bone moistures. Meat Sci., 55 255-264.

Fleming, R.H., D. Korver, H.A. McCormack and C.C. Whitehead. 2004. Assessing bone mineral density in vivo: digitized fluoroscopy and ultrasound. Poultry Sci., 83: 207-214.

Hester, P.Y., M.A. Schreiweis, J,I. Orban, H. Mazuko, M.N. Kopka, M.C. Ledur and M.E. Moody. 2004. Assessing bone mineral density in vivo: dual energy X-ray absorptiometry. Poultry Sci. 83: 215-221.

Hudson, B.P., R.J. Lien and J.B. Hess. 2000. Effects of early protein intake on development and subsequent egg production of broiler breeder hens. J. Appl. Poultry Res., 9: 324-333.

Julian, R.J. 2005. Patologias ósseas em aves. Em: Conferência Apinco 2005 de Ciência e Tecnologia Avícolas. Santos, SP. Brasil. Anais. 2: 107-122.
Kälebo, P. and K.G. Strid. 1988a. Bone mass determination from microradiographs by computer-assisted videodensitometry. Acta Radiologica, 29: 465-472.

Kälebo, P. and K.G. Strid. 1988b. Bone mass determination from microradiographs by computer-assisted videodensitometry. Acta Radiologica, 29: 611-618.

Kim, W.K., L.M. Donalson, P. Herrer, C.L. Woodward, L.F. Kubena, J.D. Nisbet and S.C. Ricke. 2004. Effects of different bone preparation methods (fresh, dry, and fat-free dry) on bone parameters and the correlations between bone breaking strength and the other bone parameters. Poultry Sci., 83: 1663-1666.

Korver, D.R., J.L. Saunders-Blades and K.L. Nodean. 2004. Assessing bone mineral density in vivo: quantitative computed tomography. Poultry Sci., 83: 222-229.

Loubel, L. y M. Dubois. 1973. Manual de densitometria: la técnica de la medición de los materiais fotográficos. $2^{\mathrm{a}}$ ed. Ediciones Omega. Barcelona. 238 p.

Louzada, M.J.Q. 1997. Densidade de peças ósseas de frangos. Estudo pela densitometria óptica radiográfica. Veterinária e Zootecnia, 9: 95109.

Maggioni, R., F. Rutz e V.F.B. Roll. 1996. Efeito do horário de fracionamento de dietas contendo diferentes níveis de cálcio sobre o desempenho produtivo e qualidade de casca em poedeiras semipesadas no verão. Em: XXXIII Reunião Anual da Sociedade Brasileira de Zootecnia, Fortaleza-CE. Anais, p. 47-49. http://www.sbz.org.br/ eventos/Fortaleza/Nut_n_rumi\%5CSbz378. pdf. Acessado em 31de julho de 2006.

Oliveira, J.R., A.G. Bertechini, E.J. Fassini, L.F.T. Albino, R.T.F. Freitas e E.T. Fialho. 2002. Níveis de cálcio para poedeiras leves e semipesadas no segundo ciclo de produção. Ciência e Agrotecnologia, 26: 1060-1067.

Onyango, E.M., P.Y. Hester, R. Stroshime and O. Adeola. 2003. Bone densitometry as am indicator of tíbia ash in broiler chickens fed varying dietary calcium and phosphorus levels. Poultry Sci., 82: 1787-1797.

Orban, J.I., S.R. Roland and M.M. Bryant. 1983. Factors influencing bone mineral content,

Archivos de zootecnia vol. 58, núm. 222, p. 182. 


\section{EFEITO DO CÁLCIO NA QUALIDADE ÓSSEA E DE OVOS DE POEDEIRAS}

density, breaking streng, and ash as response criteria for assesing bone quality in chickens. Poultry Sci., 72: 437-56.

Qin, X. and H. Klandorf. 1991. Effect of dietary boron supplementation on egg production, shell quality, and calcium metabolism in aged broiler breeder hens. Poultry Sci., 70: 2131-2138.

Robinson, F.E., J.L. Wilson and M.W. Yu. 1993. The relationship between body weight and reproductive efficiency in meat-type chickens. Poultry Sci., 72: 912-922.

SAEG. 1998. Sistema para análise estatística e genéticas. Manual de utilização do programa SAEG. UFV. Viçosa. $59 \mathrm{p}$.

Schreiweis, M.A., J.I. Orban, M.C. Ledur and P.Y. Hester. 2003. The use densitometry to detect differences in bone mineral density and content of live white Leghorns fed varying levels of dietary calcium. Poultry Sci., 82: 1292-1301.

Schreiweis, M.A., J.I. Orban, M.C. Ledur, D.E. Moody and P.Y. Hester. 2004. Effects of ovulatory and egg laying cycle on bone mineral density and content White Leghorns as assessed by dual-energy $\mathrm{x}$-ray absorptiometry. Poultry Sci., 83: 1011-1019.

Shaver Brown. 2005. Guia de manejo de ponedoras. www.isapoultry.com. Acessado em 02 de fevereiro de 2006. $26 \mathrm{p}$.

Seedor, J.G. 1995. The biophosphanate alendronate (MK-217) inhibit bone loss due to ovariectomy in rats. J. Bone Miner. Res., 4: 265270.

Zhang, B. and C.N. Coon. 1997. The relationship of calcium intake, source, size, solubility in vitro and in vivo, and gizzard limestone retention in laying hens. Poultry Sci., 76: 1702-1706. 